that home-grown graduates in science and engineering often choose to go straight into high-paying local jobs rather than pursue postgraduate research. Singapore is trying to rectify this by topping up incomes for local graduate students to persuade the brightest to stay. 'Accelerated' courses are also offered, to hasten students to a masters degree in the time it takes to get an undergraduate degree.

But it is an "uphill struggle", says Bernard Tan, dean of science at the National University of Singapore (NUS). Because many of the leaders of the new institutions are of Chinese ethnic background, it is only natural that through their connections they recruit Chinese scientists from around the world. It is not that Chinese scientists are being targeted for positions - NUS also recruits many Indian scientists and has a cosmopoli$\tan$ mix of faculty, as does HKUST. The Chinese are just such a "huge pool" says Tan. Furthermore, "how many non-Chinese want to come to Hong Kong?", points out HKUST president Chia-Wei Woo.

For Taiwan, the situation is rather different. Taiwanese students have a long tradition of pursuing graduate study. For many years this was done in the United States, but graduate schools in Taiwan are now quite strong, with more than 40,000 students (see opposite). Also, in contrast to Singapore and Hong Kong, it is harder for Taiwan to establish research links with the mainland because of the present political climate, and so the United States remains the key source of scientists and research links.

\section{Job squeeze in the West}

A complicating factor is the recent tightening of the job situation for researchers in the United States. This is particularly the case in companies like IBM and Bell Laboratories that have employed many Chinese, but which in the past few years have scaled back their basic research operations, causing many to move to universities or back to Asia. However, the majority of Chinese mainland scientists still prefer to stay in the United States (see page 14).

Europe is not such a strong magnet. Nevertheless, there are thousands of Chinese scientists there, particularly at the graduate and postdoctoral level. But, unlike the United States, there are very few job opportunities beyond the postdoctoral level, and thus there is a stronger tendency for Chinese in Europe to seize opportunities to return to Asia.

Many recent young returnees to Asia await their opportunity to go back to China itself. "China welcomes top people back," says Yan Hong, who has taken up a position at the new Institute of Molecular Agrobiology at NUS in Singapore after doing postdoctoral research at a company in the United States. "I hope to return when I have established a name for myself and can head a laboratory."

Cultural factors also play a role. Many returnees have a strong mission to give something back to China. A notable example is Chen Ning Yang, Nobel prize winner for physics in 1957 for his work on weak interactions, who now holds a joint appointment at the Chinese University in Hong Kong and the State University of New York at Stony Brook. When he visited China in 1972, having left in 1945, he says that he decided he had "a responsibility to help build a bridge between the two countries ... to help China in her drive towards developing science and technology".

Returnees like Yang are building links with researchers in China as a means of fulfilling their dream of helping the motherland. As a result, there is an influx of Chinese scientists direct from the mainland to the booming economies of Asia. At NUS, for example, 60-75 per cent of the rapidly growing population of over 1,000 graduate students in science and engineering are from the mainland. The same is true of the nascent population of postdoctoral fellows.

Strong family ties are another factor bringing people back. "The fundamental unit in Chinese culture is not the individual, it is the family," says Yang. "To return to the family is not only the most desirable thing, it's the only proper thing." Fong Shih, who after 30 years in the United States is returning to Singapore to head the soon-to-beopened Institute of Materials Research and Engineering at NUS, points out that many returnees in their late forties and fifties have

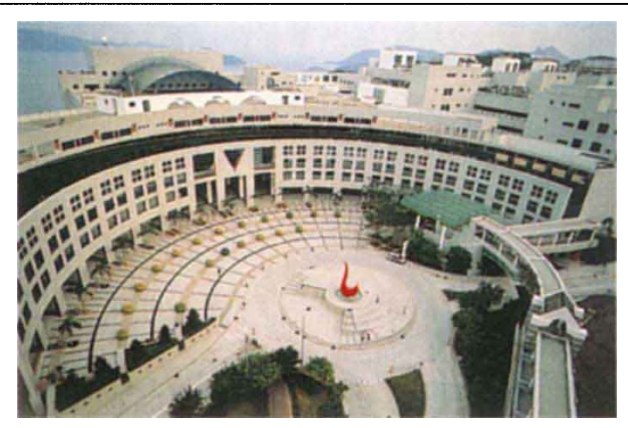

Hong Kong University of Science and Technology (HKUST) is one of the most dramatic examples of new institutions that have drawn Chinese scientists back to Asia. Opened in 1991, it has rapidly expanded its faculty members to more than 500 , over 80 per cent of them of Chinese descent. The majority have come from top institutions in the United States and a few from Europe. But many of these - about a hundred - originally came from the Chinese mainland, where they did their undergraduate degrees before going to the West. There are also about 100 visiting faculty from the Chinese mainland, and about 160 of the approximately 1,000 graduate students are from the mainland, too.

parents in their seventies. "They want to come home before they go to heaven."

Shih, an ethnic Chinese from Singapore, "struggled" over his decision to return. With a PhD from Harvard, he has a tenured position at Brown University, NSF grants and PhD students. But in Singapore he can start "from scratch". "Some of the best minds in the United States are Asians. Many are now returning and next century we will compete at a very high level with the West."

David Swinbanks \& Elisabeth Tacey

\title{
Collaboration with mainland China
}

RETURNEES who have their roots in China are particularly keen to develop research links with the mainland. One example is Leroy Chang, the dean of science at Hong Kong University of Science and Technology (HKUST). Born in Henan in 1937, Chang migrated first to Taiwan at the time of the communist takeover. After an undergraduate degree at Taiwan National University, he went to the United States, first to a small university and then to Stanford University to a do $\mathrm{PhD}$. He then spent 30 years at IBM Watson (with a Chang: forging links one-year break at MIT), where with mainland China. he gained fame for his research on quantum wells and superlattices. He joined HKUST in 1993.

Chang says that, although he didn't know it, he was just "following the crowd". One of his compatriots, for example, Bill Chen who also went to Taiwan National University after fleeing the mainland, then to Stanford, and ended up at Bell Laboratories working in microelectronics for 26 years, is now in Singapore heading the Institute of Micro-

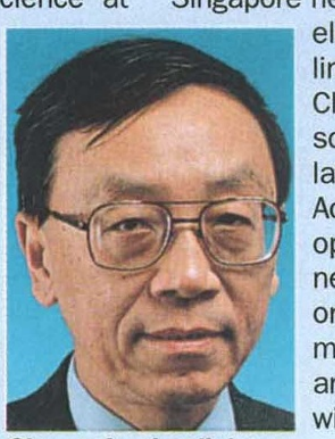
1975 when he visited China with a small group of top US physicists. "That really made a difference... I was the only Chinese and after I returned to IBM, many Chinese came every year to see me," he says. "Now these people are presidents of universities and institutes. So collaborating is very easy. We have known each other for years." D.S. 